\title{
Vitamin D Status Is Not Associated with Cognitive or Motor Function in Pre-School Ugandan Children
}

\author{
Agnes M. Mutua ${ }^{1, * \mathbb{D}}$, Margaret Nampijja ${ }^{2,3}\left(\mathbb{D}\right.$, Alison M. Elliott ${ }^{3,4}$, John M. Pettifor ${ }^{5}$ (D), \\ Thomas N. Williams 1,6,7 (D), Amina Abubakar 1,8,9,10, Emily L. Webb ${ }^{11} \mathbb{D}$ and \\ Sarah H. Atkinson $1,7,12, *$ (D)
}

1 Kenya Medical Research Institute (KEMRI), Centre for Geographic Medicine Research-Coast, KEMRI Wellcome Trust Research Programme, P.O. BOX 230-80108 Kilifi, Kenya; Tom.n.williams@gmail.com (T.N.W.); AAbubakar@kemri-wellcome.org (A.A.)

2 Maternal and Child Wellbeing (MCW) Unit, African Population and Health Research Center, P.O. Box 10787-00100 Nairobi, Kenya; maggie.nampijja@gmail.com

3 Medical Research Council/Uganda Virus Research Institute and London School of Hygiene and Tropical Medicine Uganda Research Unit, P.O. Box 49, Entebbe, Uganda; Alison.Elliott@lshtm.ac.uk

4 Department of Clinical Research, London School of Hygiene and Tropical Medicine, London WC1E 7HT, UK

5 South African Medical Research Council and Wits Developmental Pathways for Health Research Unit, Department of Paediatrics, University of the Witwatersrand, 26 Chris Hani Road, Soweto 6201, Johannesburg, South Africa; John.Pettifor@wits.ac.za

6 Department of Medicine, Imperial College of Science Technology and Medicine, St Mary's Hospital, London W2 1NY, UK

7 Centre for Tropical Medicine and Global Health, Nuffield Department of Medicine, University of Oxford, Oxford OX3 7FZ, UK

8 Department of Public Health, School of Human and Health Sciences, Pwani University, P.O. BOX 195-80108 Kilifi, Kenya

9 Department of Psychiatry, University of Oxford, Oxford OX3 7JX, UK

10 Institute for Human Development, Aga Khan University, 2nd Parklands Avenue, P.O. BOX 30270-00100 Nairobi, Kenya

11 MRC Tropical Epidemiology Group, Department of Infectious Disease Epidemiology, London School of Hygiene and Tropical Medicine, London WC1E 7HT, UK; Emily.Webb@lshtm.ac.uk

12 Department of Paediatrics, University of Oxford, Oxford OX3 9DU, UK

* Correspondence: AMutua@kemri-wellcome.org (A.M.M.); SAtkinson@kemri-wellcome.org (S.H.A.); Tel.: +254-709983677/76 (A.M.M.)

Received: 21 April 2020; Accepted: 27 May 2020; Published: 3 June 2020

\begin{abstract}
Vitamin D deficiency is common worldwide and young children are among the most affected groups. Animal studies suggest a key role for vitamin D in brain development. However, studies investigating the effects of vitamin D on neurobehavioural outcomes in children are inconclusive and evidence is limited in sub-Saharan Africa. We evaluated the effect of vitamin D status on cognitive and motor outcomes using prospective data from the Entebbe Mother and Baby Study birth cohort. We analysed data from 302 Ugandan children with 25-hydroxyvitamin D (25(OH)D) measurements below five years and developmental measures at five years of age. We used multivariable linear regression, adjusted for potential confounders, to estimate the effect of $25(\mathrm{OH}) \mathrm{D}$ on cognitive and motor outcomes. Of 302 children, eight $(2.7 \%)$ had $25(\mathrm{OH}) \mathrm{D}$ levels $<50 \mathrm{nmol} / \mathrm{L}, 105(35.8 \%)$ had levels $50-75 \mathrm{nmol} / \mathrm{L}$ and $189(62.6 \%)$ had levels $>75 \mathrm{nmol} / \mathrm{L}$. There was no evidence that earlier vitamin $\mathrm{D}$ status was associated with cognitive and motor outcomes in five-year-old Ugandan children. This study adds to the sparse literature and highlights the need for further longitudinal studies on vitamin $\mathrm{D}$ and neurobehavioural outcomes in children living in sub-Saharan Africa.
\end{abstract}

Keywords: vitamin D; cognitive function; motor function; children; Africa 


\section{Introduction}

The first five years in a child's life are a period of rapid brain development [1]. About 81 million children aged three to four years have poor cognitive and socioemotional development in low and middle-income countries worldwide and 29.4 million of these children live in sub-Saharan Africa [2]. Therefore, mitigation of recognized risk factors for impaired development, including infections, inadequately stimulating home environments and malnutrition, is necessary [3]. Evidence indicates that micronutrient deficiencies may also be an important risk factor for impaired neurobehavioural outcomes [4]. Vitamin D deficiency and/or insufficiency is prevalent among populations worldwide [5,6] and children are among the most at-risk groups for sub-optimal 25-hydroxyvitamin D $(25(\mathrm{OH}) \mathrm{D})$ levels $[7,8]$. A recent systematic review and meta-analysis of vitamin D deficiency in Africa reported a pooled prevalence of vitamin D deficiency $(25(\mathrm{OH}) \mathrm{D}$ levels $<50 \mathrm{nmol} / \mathrm{L})$ of $49.1 \%$ among newborns and $23.0 \%$ among children below 18 years of age [9].

Vitamin D may influence neurobehavioural outcomes through its role in brain development. The presence of vitamin D receptors and metabolites in cerebrospinal fluid and parts of the brain including the hippocampus and the cortex may indicate a key role for vitamin D in brain development [10]. Vitamin D deficiency is also associated with structural and functional alterations in the developing brains of rodents, which are associated with impaired behaviour, learning, motor and cognitive processes [11-13]. Furthermore, vitamin D appears to plays a role in neuroprotection through its anti-inflammatory properties in the brain [14]. There are few epidemiological studies of the effect of vitamin D status on neurobehavioural outcomes in children and their findings are inconsistent [15]. One small randomized controlled trial, without a placebo arm, reported a beneficial effect of supplementation with lower doses of vitamin D compared to higher doses [16] while another found no beneficial effect of vitamin D supplementation on cognitive development in extremely preterm infants compared to no supplementation [17].

Only two studies have investigated the relationship between the vitamin D status of children and their neurobehavioural outcomes in Africa, and these were in school-aged children. A prospective study of 254 Ugandan children reported associations between $25(\mathrm{OH})$ D levels and socio-emotional adjustment outcomes among school-children who were stratified according to perinatal HIV exposure/infection and in utero/peripartum antiretroviral exposure [18], while a cross-sectional study of 45 Egyptian school-children reported a positive association between higher $25(\mathrm{OH}) \mathrm{D}$ levels and improved cognition and school performance compared to lower levels [19]. Our study aimed to evaluate the association between vitamin D status and cognitive and motor outcomes in pre-school Ugandan children using data from the Entebbe Mother and Baby Study (EMaBS) prospective birth cohort. We analysed data from 302 community-based children with 25(OH)D measurements below five years of age and cognitive and motor development assessed at five years of age.

\section{Materials and Methods}

\subsection{Ethical Approval}

Ethical approval was given by the Medical Research Council (MRC)/Uganda Virus Research Institute Research Ethics Committee (reference numbers: GC/127 and GC/127/15/04/35), Uganda National Council for Science and Technology and the London School of Hygiene and Tropical Medicine Ethics Committee (reference numbers: 790 and 17261). Parents or guardians provided informed consent in writing, or with a thumbprint if not literate with a signature from a literate witness.

\subsection{Participants and Study Design}

The Entebbe Mother and Baby Study (EMaBS) prospective birth cohort was initially designed as a double-blind randomized controlled trial of the effects of anthelmintic treatment during pregnancy and early childhood on immunological and disease outcomes in childhood (ISRCTN32849447). Details of the study are described elsewhere [20]. Briefly, between April 2003 and November 2005, 2507 pregnant 
women were recruited into the study during their first antenatal care clinic visit at Entebbe hospital and randomized to receive either albendazole or placebo and praziquantel or placebo in a $2 \times 2$ factorial design. Their children formed the EMaBS birth cohort that was followed up from birth and seen during scheduled annual visits or when they were sick. The children were randomized to receive albendazole or placebo from the age of 15 months to five years and children with helminth infection detected at annual visits were treated according to clinical guidelines. Data on sex, birthweight, gestational age and anthropometric measurements were recorded and blood samples were taken at birth and during annual visits. Children were brought to the study clinic for diagnosis and treatment when they were unwell. Information on maternal age, socioeconomic status, location, education, parity and medical conditions was collected at enrolment. Household socioeconomic status was derived as a composite of building materials of the home, number of rooms and items owned. A total asset score was calculated and categorized into 6 ordered categorical levels with 1 indicating lowest and 6 indicating highest household socioeconomic status.

\subsection{Sample Size}

In the larger EMaBS study, the cohort size of 2500 was determined based on the primary immunological objectives. For the present sub-study, assuming a prevalence of $36.6 \%$ of $25(\mathrm{OH}) \mathrm{D}$ levels $\leq 75 \mathrm{nmol} / \mathrm{L}$ among Ugandan children [21] and a standard deviation of two in cognitive and motor scores [22], our sample size of 302 has $80 \%$ power at $\alpha=0.05$ to detect a difference of 0.7 when comparing mean cognitive/motor scores between the $25(\mathrm{OH}) \mathrm{D}$ levels $\leq 75 \mathrm{nmol} / \mathrm{L}$ and $>75$ nmol/L groups.

\subsection{Laboratory Procedures and Definitions}

Stored blood samples were analysed based on availability with most samples being from two years of age. The biomarkers assayed were plasma 25(OH)D (Chemiluminescent Microparticle Immunoassay (CMI), Abbott Architect), ferritin (CMI, Abbott Architect), haemoglobin (Medonic CA 530) and C-reactive protein (CRP, MULTIGENT CRP Vario assay, Abbott Architect) [23]. For this study, we classified 25(OH)D levels into three categories; levels $<50 \mathrm{nmol} / \mathrm{L}, 50-75 \mathrm{nmol} / \mathrm{L}$ and $>75 \mathrm{nmol} / \mathrm{L}$, according to the Endocrine Society Practice Guidelines [24]. We defined iron deficiency as plasma ferritin $<12 \mu \mathrm{g} / \mathrm{L}$ and inflammation as CRP levels $>5 \mathrm{mg} / \mathrm{L}$. Anaemia was defined as haemoglobin levels $<11 \mathrm{~g} / \mathrm{dL}$, after subtracting $0.2 \mathrm{~g} / \mathrm{dL}$ from all haemoglobin values to adjust for altitude (1000 m above sea level). Malaria parasitaemia was measured using Giemsa-stained thick and thin blood smears and a malaria episode was defined as parasitaemia and temperature $>37.5^{\circ} \mathrm{C}$. All children were tested annually for asymptomatic malaria and the study included longitudinal active surveillance for malaria and other infections during fortnightly home visits and quarterly clinic visits. Children of HIV-positive mothers were tested for HIV at six weeks and 18 months using a filter-paper blood spot for DNA-PCR, a measure for HIV-antibodies and viral RNA.

\subsection{Cognitive and Motor Assessments}

At age five years, cognitive and motor tests were performed at the EMaBS clinic by trained nurses and doctors in 60-90-min sessions including breaks. Of the 13 measures used to assess cognitive and motor abilities at five years, four (counting span, running memory, shapes task and tower of London) were excluded in this analysis as they were administered to a small sub-set of children $(n<113)$. We combined the remaining nine individual measures using principal components analysis to generate scores on three components of child development; verbal and non-verbal intelligence quotient (IQ), executive function (EF) and motor function. We excluded two measures (tap one tap twice task and sentence repetition) that did not load well on the IQ, EF or motor function components. We excluded one recorded observation in the coinbox test and another in the balancing on one leg test as they were beyond the maximum attainable scores for the respective measures. Details of the translation and validation of all of the neurobehavioural measures in the Ugandan setting are described elsewhere [25]. 
In a small pilot study, involving children not in the current study, the measures had good internal consistency (Cronbach's alpha $=0.65-0.82$ ) and test-retest reliability (correlation coefficient $(r)=0.45$ - 0.88), except the Wisconsin card sort test $(\mathrm{r}=0.22)$ which was administered to only 19 children in the pilot study [25]. The measures used for the current study are briefly described in Table 1.

Table 1. Description of the cognitive and motor measures used in the study.

\begin{tabular}{|c|c|c|c|c|}
\hline $\begin{array}{c}\text { PCA } \\
\text { Components }\end{array}$ & Name of Test & Domain & Description of Measure & $\begin{array}{l}\text { Absolute Scores } \\
\text { (Min, Max) }\end{array}$ \\
\hline \multirow[t]{2}{*}{$\begin{array}{c}\text { Verbal and } \\
\text { non-verbal IQ }\end{array}$} & Block design & Non-verbal IQ & $\begin{array}{l}\text { The measure is adapted from the British } \\
\text { Ability Scales-third edition [26]. The } \\
\text { child is asked to copy and construct } \\
\text { items with wooden blocks following a } \\
\text { demonstration by the assessor. }\end{array}$ & 0,16 \\
\hline & $\begin{array}{l}\text { Picture vocabulary } \\
\text { scale }\end{array}$ & Verbal IQ & $\begin{array}{l}\text { The measure is adapted from the Kilifi } \\
\text { Vocabulary Test [27]. The child is asked } \\
\text { to point out and identify items from } 24 \\
\text { black and white picture items familiar } \\
\text { to them. }\end{array}$ & 0,24 \\
\hline \multirow[t]{3}{*}{$\begin{array}{l}\text { Executive } \\
\text { function }\end{array}$} & Verbal fluency & $\begin{array}{l}\text { Working } \\
\text { memory }\end{array}$ & $\begin{array}{l}\text { The measure is adapted from the } \\
\text { Developmental NEuroPSYchological } \\
\text { Assessment [28]. The child is asked to } \\
\text { name items including foods and } \\
\text { animals as fast as possible in a minute. }\end{array}$ & $*$ \\
\hline & Picture search & $\begin{array}{l}\text { Selective } \\
\text { attention }\end{array}$ & $\begin{array}{l}\text { The measure is adapted from the Sky } \\
\text { Search in Tests of Everyday Attention } \\
\text { for Children [29]. The child is presented } \\
\text { with three A3 sheets each with a target } \\
\text { picture on top and about } 100 \text { others at } \\
\text { the bottom including copies of the } \\
\text { target picture. The child is asked to } \\
\text { locate as many copies of the target } \\
\text { pictures as possible within } 10 \mathrm{~s} \text {. }\end{array}$ & $* *$ \\
\hline & $\begin{array}{c}\text { Wisconsin card sort } \\
\text { test }\end{array}$ & $\begin{array}{l}\text { Cognitive } \\
\text { flexibility }\end{array}$ & $\begin{array}{l}\text { The measure is adapted from Berg's } \\
\text { card sort test [30]. The child is given } \\
\text { four playing cards of different suits and } \\
\text { a pack of } 12 \text { cards and asked to sort the } \\
\text { cards by number (block } 1 \text { ) and suit } \\
\text { (block 2). }\end{array}$ & 0,12 \\
\hline \multirow[t]{2}{*}{ Motor function } & Coin box & $\begin{array}{l}\text { Fine motor } \\
\text { function }\end{array}$ & $\begin{array}{l}\text { The measure is adapted from the Kilifi } \\
\text { Developmental Inventory [31]. The } \\
\text { child is asked to slot coins through a } \\
\text { small opening on a coinbox within } 20 \mathrm{~s} \\
\text { in two trials. }\end{array}$ & $0,20+$ \\
\hline & $\begin{array}{l}\text { Balancing on one } \\
\text { leg }\end{array}$ & $\begin{array}{l}\text { Gross motor } \\
\text { function }\end{array}$ & $\begin{array}{l}\text { The measure is adapted from the } \\
\text { Movement Assessment Battery for } \\
\text { Children [32]. It entails timed attempts } \\
\text { (two per leg) of balancing on one leg for } \\
\text { one minute. }\end{array}$ & $0,60+$ \\
\hline
\end{tabular}

PCA, principal components analysis; IQ, intelligence quotient; Min, minimum score; Max, maximum score. *One point is awarded for each correct name and a total score is calculated from the total correct names in a minute. ${ }^{* *} \mathrm{~A}$ total score is calculated from the number of target pictures identified within $10 \mathrm{~s}$. + An average score is calculated after timed attempts of the tests. Block design and picture vocabulary tests loaded heavily on verbal and non-verbal IQ while verbal fluency, picture search and Wisconsin card sort tests loaded heavily on executive function. Coinbox and balancing on one leg tests loaded heavily on motor function. The resulting scores were centred on zero with higher scores representing better and lower scores worse development.

\subsection{Statistical Analysis}

All analyses were conducted using STATA version 15.0 (StataCorp, College Station, TX 77845, United States of America). We assessed the distribution of 25(OH)D levels and developmental scores using histograms and scatterplots. We examined the characteristics of the participants using descriptive statistics including proportions and means with standard deviations and used ANOVA to compare mean scores between children with 25(OH)D levels $<50 \mathrm{nmol} / \mathrm{L}, 50-75 \mathrm{nmol} / \mathrm{L}$ and $>75 \mathrm{nmol} / \mathrm{L}$. We 
compared baseline characteristics of children included in these analyses $(n=302)$ and those who were not included ( $n=2043$ ). Of the 2043 children, 594 were lost to follow-up, 116 died, 312 did not attend their fifth annual visit, 540 did not have cognitive and motor outcome data and 481 children did not have data on $25(\mathrm{OH}) \mathrm{D}$ levels prior to five years of age.

We used univariable and multivariable linear regression models to estimate the effect of vitamin D in early childhood on cognitive and motor outcomes at five years. We identified potential confounders from literature including age at $25(\mathrm{OH}) \mathrm{D}$ measurement, sex, iron status and anaemia (haemoglobin levels $<11 \mathrm{~g} / \mathrm{dL}$ ), inflammation (CRP levels $>5 \mathrm{mg} / \mathrm{L}$ ), height-for-age Z-scores, randomized treatment of children with albendazole, socioeconomic status, maternal education and asymptomatic malaria parasitaemia. We empirically tested associations of the potential confounders identified from literature in addition to weight-for-age and weight-for-height Z-scores, location, maternal age, parity and randomized maternal treatment with albendazole and praziquantel with $25(\mathrm{OH}) \mathrm{D}$ levels and cognitive and motor outcomes using multivariable linear regression models. Then, using a forward modelling approach, we fitted three separate linear regression models for each outcome starting with separate crude models with $25(\mathrm{OH}) \mathrm{D}$ levels as the exposure variable (included as a continuous variable, per $10 \mathrm{nmol} / \mathrm{L}$ increase) for each of the three outcomes. Then we generated minimally adjusted models with age at vitamin D measurement, sex, iron and anaemia status included as potential confounders. Finally, we added other potential confounders one by one to the minimally adjusted models observing the change in regression coefficients until final multivariable models for each of the three outcomes were generated. We re-ran these final models, fitting vitamin $\mathrm{D}$ as a categorical variable $(25(\mathrm{OH}) \mathrm{D}$ levels $\leq 75 \mathrm{nmol} / \mathrm{L}$ compared to levels $>75 \mathrm{nmol} / \mathrm{L}$ ). We were unable to further investigate associations with $25(\mathrm{OH}) \mathrm{D}$ levels $<50 \mathrm{nmol} / \mathrm{L}$ using multivariable analysis since few children $(n=8)$ had $25(\mathrm{OH}) \mathrm{D}$ levels $<50 \mathrm{nmol} / \mathrm{L}$, so children with $25(\mathrm{OH}) \mathrm{D}$ levels $<50 \mathrm{nmol} / \mathrm{L}$ were grouped with children that had levels $50-75 \mathrm{nmol} / \mathrm{L}$. We also compared children with $25(\mathrm{OH}) \mathrm{D}$ levels $50-75 \mathrm{nmol} / \mathrm{L}$ with children that had levels $>75 \mathrm{nmol} / \mathrm{L}$.

Due to missing observations in haemoglobin (16 missing values) and ferritin levels (14 missing values), we assessed whether excluding these variables in final models impacted results. We examined multicollinearity using the variance inflation factor (VIF) which measures change in the regression coefficient if predictor variables are correlated, with a VIF $>10$ suggesting severe multicollinearity. None of the variables had a VIF > 2 in any model although clinical malaria episodes and asymptomatic malaria parasitaemia appeared to be moderately correlated and we therefore, only adjusted for asymptomatic malaria parasitaemia.

\section{Results}

\subsection{Description of Study Participants}

A total of 302 children, $48.3 \%$ boys and $51.7 \%$ girls were included in this study. None of the included children or their mothers received vitamin D supplementation. Characteristics of the study participants are presented in Table 2. Most children $(68.2 \%)$ had $25(\mathrm{OH}) \mathrm{D}$ levels measured at the second annual visit (mean age $=2.3$ years, standard deviation $(\mathrm{SD})=0.7$ ) and mean age at cognitive and motor assessment was $5.0(\mathrm{SD}=0.02$ ) years. Mean $(\mathrm{SD})$ and median (interquartile range) $25(\mathrm{OH}) \mathrm{D}$ levels were 83.2 (22.2) nmol/L and 81.0 (67.9 to 95.5) nmol/L, respectively. Eight (2.7\%) children had 25(OH)D levels $<50 \mathrm{nmol} / \mathrm{L}, 105$ (34.8\%) had levels 50-75 nmol/L and 189 (62.6\%) had levels $>75 \mathrm{nmol} / \mathrm{L}$. 
Table 2. Baseline characteristics stratified by 25(OH)D levels of 302 Ugandan children included in the analysis and multivariable linear regression results for associations between $25(\mathrm{OH}) \mathrm{D}$ and participant characteristics.

\begin{tabular}{|c|c|c|c|c|c|}
\hline Characteristics & $\begin{array}{c}\text { All } \\
\text { Participants }\end{array}$ & $\begin{array}{c}25(\mathrm{OH}) \mathrm{D} \\
\text { Levels } \leq 75 \\
\text { nmol/L) } \\
(n=113)\end{array}$ & $\begin{array}{l}25(\mathrm{OH}) \mathrm{D} \\
\text { Levels }>75 \\
\text { nmol/L } \\
(n=189)\end{array}$ & $\begin{array}{c}\text { 25(OH)D Levels } \\
\text { (Per } 10 \text { nmol/L) } \\
(n=295) \beta \\
(95 \% \text { CI })+\dagger\end{array}$ & $p$ Value \\
\hline \multicolumn{6}{|l|}{$\begin{array}{c}\text { Age at } 25(\mathrm{OH}) \mathrm{D} \\
\text { measurement in years, } \\
(n, \%)\end{array}$} \\
\hline 1 & $10(3.3)$ & $3(30.0)$ & $7(70.0)$ & $0.91(-0.79,2.62)$ & $0.02 *$ \\
\hline 2 & $206(68.2)$ & $75(36.4)$ & $131(63.6)$ & Reference & \\
\hline 3 & $63(20.9)$ & $24(38.1)$ & $39(61.9)$ & $-0.49(-1.19,0.19)$ & \\
\hline 4 & $23(7.6)$ & $11(47.8)$ & $12(52.2)$ & $-1.31(-2.72,0.11)$ & \\
\hline \multicolumn{6}{|l|}{$\operatorname{Sex}(n, \%)$} \\
\hline Male & $146(48.3)$ & $56(38.4)$ & $90(61.6)$ & Reference & \\
\hline Female & $156(51.7)$ & $57(36.5)$ & 99 (63.5) & $-0.29(-0.82,0.24)$ & 0.29 \\
\hline \multicolumn{6}{|l|}{$\begin{array}{l}\text { Height-for-age Z-scores } \\
\qquad(\mathrm{mv}=8)\end{array}$} \\
\hline Normal (>2 SD) & $193(65.7)$ & 79 (40.9) & $114(59.1)$ & Reference & \\
\hline Stunted (<2 SD) & $101(34.4)$ & $32(31.7)$ & $69(68.3)$ & $0.21(-0.36,0.78)$ & 0.47 \\
\hline \multicolumn{6}{|l|}{$\begin{array}{l}\text { Weight-for-age Z-scores } \\
\qquad(\mathrm{mv}=5)\end{array}$} \\
\hline Normal (>2 SD) & $264(88.9)$ & $103(39.0)$ & $161(61.0)$ & Reference & \\
\hline Underweight $(<2 \mathrm{SD})$ & $33(11.1)$ & $8(24.2)$ & $25(75.8)$ & $0.33(-0.57,1.23)$ & 0.47 \\
\hline \multicolumn{6}{|l|}{$\begin{array}{c}\text { Weight-for-height } \\
\text { Z-scores } \\
(\mathrm{mv}=5)\end{array}$} \\
\hline Normal (>2 SD) & $283(95.3)$ & $105(37.1)$ & $178(62.9)$ & Reference & \\
\hline Wasted (<2 SD) & $14(4.7)$ & $6(42.9)$ & $8(57.1)$ & $-0.50(-1.84,0.84)$ & 0.46 \\
\hline \multicolumn{6}{|l|}{$\begin{array}{l}\text { Helminthic infections } \\
\text { between birth and } 5 \\
\text { years }(n, \%)\end{array}$} \\
\hline Negative & $248(82.1)$ & $96(38.7)$ & $152(61.3)$ & Reference & \\
\hline Positive & $54(17.9)$ & $17(31.5)$ & $37(68.5)$ & $0.01(-0.74,0.76)$ & 0.98 \\
\hline \multicolumn{6}{|l|}{$\begin{array}{l}\text { Asymptomatic malaria } \\
\text { between birth and } 5 \\
\text { years }(n, \%)\end{array}$} \\
\hline Negative & $268(88.7)$ & $103(38.4)$ & $165(61.6)$ & Reference & \\
\hline Positive & $34(11.3)$ & $10(29.4)$ & $24(70.6)$ & $1.14(0.27,2.02)$ & 0.01 \\
\hline \multicolumn{6}{|l|}{$\begin{array}{c}\text { Malaria episodes } \\
\text { between birth and } 5 \\
\text { years }(n, \%)\end{array}$} \\
\hline None & $135(44.7)$ & $56(41.8)$ & $79(58.5)$ & Reference & \\
\hline 1 & $65(21.5)$ & $24(36.9)$ & $41(63.1)$ & $-0.38(-1.12,0.36)$ & \\
\hline$\geq 2$ & $102(33.8)$ & $33(32.3)$ & $69(67.7)$ & $0.25(-0.38,0.89)$ & $0.48^{*}$ \\
\hline \multicolumn{6}{|l|}{$\begin{array}{l}\text { Haemoglobin levels at } \\
\text { time of } 25(\mathrm{OH}) \mathrm{D} \\
\text { measurement }{ }^{\mathrm{a}}(n, \%) \\
(\mathrm{mv}=16)\end{array}$} \\
\hline Normal & $172(60.1)$ & $62(36.1)$ & $110(63.9)$ & Reference & \\
\hline Anaemia & $114(39.9)$ & $44(38.6)$ & $70(61.4)$ & $-0.17(-0.74,0.40)$ & 0.56 \\
\hline \multicolumn{6}{|l|}{$\begin{array}{l}\text { Iron deficiency at time of } \\
25(\mathrm{OH}) \mathrm{D} \text { measurement }{ }^{\mathrm{b}} \\
(n, \%)(\mathrm{mv}=14)\end{array}$} \\
\hline Normal & $210(72.9)$ & $76(36.2)$ & $134(63.8)$ & Reference & \\
\hline Iron deficiency & $78(27.1)$ & $31(39.7)$ & $47(60.3)$ & $0.03(-0.60,0.66)$ & 0.93 \\
\hline
\end{tabular}


Table 2. Cont

\begin{tabular}{|c|c|c|c|c|c|}
\hline Characteristics & $\begin{array}{c}\text { All } \\
\text { Participants }\end{array}$ & $\begin{array}{c}25(\mathrm{OH}) \mathrm{D} \\
\text { Levels } \leq 75 \\
\text { nmol/L) } \\
(n=113)\end{array}$ & $\begin{array}{c}25(\mathrm{OH}) \mathrm{D} \\
\text { Levels }>75 \\
\text { nmol/L } \\
(n=189)\end{array}$ & $\begin{array}{c}\text { 25(OH)D Levels } \\
\text { (Per } 10 \text { nmol/L) } \\
(n=295) \beta \\
(95 \% \mathrm{CI})++\end{array}$ & $p$ Value \\
\hline \multicolumn{6}{|c|}{$\begin{array}{c}\text { CRP levels at time of } \\
25(\mathrm{OH}) \mathrm{D} \text { measurement } \\
(n, \%)(\mathrm{mv}=3)\end{array}$} \\
\hline Normal & $230(76.9)$ & $98(42.6)$ & $132(57.4)$ & Reference & \\
\hline Inflammation & $69(23.1)$ & $15(21.7)$ & $54(78.3)$ & $0.79(0.14,1.46)$ & 0.02 \\
\hline \multicolumn{6}{|c|}{ Randomized treatment of children with albendazole (ABZ) in EMaBS trial } \\
\hline Placebo & $143(47.4)$ & $53(37.1)$ & $90(62.9)$ & Reference & \\
\hline ABZ & $159(52.7)$ & $60(37.7)$ & $99(62.3)$ & $0.13(-0.41,0.67)$ & 0.63 \\
\hline \multicolumn{6}{|c|}{ Maternal age in years at enrolment to $\operatorname{EMaBS}(n, \%)$} \\
\hline $14-24$ & $165(54.6)$ & $63(38.2)$ & $102(61.8)$ & Reference & \\
\hline $25-34$ & $110(36.4)$ & $40(36.4)$ & $70(63.6)$ & $-0.09(-0.77,0.59)$ & \\
\hline $35+$ & $27(8.9)$ & $10(37.0)$ & $17(63.0)$ & $0.69(-0.54,1.91)$ & $0.55 *$ \\
\hline \multicolumn{6}{|c|}{ Maternal education at enrolment to $\operatorname{EMaBS}(n, \%)(\mathrm{mv}=1)$} \\
\hline Primary/none & $165(54.8)$ & $66(40.0)$ & $99(60.0)$ & $0.19(-0.91,1.29)$ & \\
\hline Secondary & $114(37.9)$ & $37(32.5)$ & $77(67.5)$ & $0.46(-0.64,1.56)$ & \\
\hline Tertiary & $22(7.3)$ & $9(40.9)$ & $13(59.1)$ & Reference & $0.77 *$ \\
\hline \multicolumn{6}{|l|}{ Parity $(n, \%)$} \\
\hline 1 & $54(17.9)$ & $27(50.0)$ & $27(50.0)$ & Reference & \\
\hline $2-4$ & $179(59.3)$ & $61(34.1)$ & $118(65.9)$ & $0.19(-0.56,0.94)$ & \\
\hline $5+$ & $69(22.9)$ & $25(36.2)$ & $44(63.8)$ & $-0.09(-1.23,1.05)$ & $0.97 *$ \\
\hline \multicolumn{6}{|c|}{ Randomized treatment of mothers with ABZ during pregnancy in EMaBS trial $(n, \%)$} \\
\hline Placebo & $144(47.7)$ & $51(35.4)$ & $93(64.6)$ & Reference & \\
\hline ABZ & $158(552.3)$ & $62(39.2)$ & $96(60.8)$ & $-0.02(-0.56,0.52)$ & 0.94 \\
\hline \multicolumn{6}{|c|}{ Randomized treatment of mothers with praziquantel during pregnancy in EMaBS trial $(n, \%)$} \\
\hline Placebo & $167(55.3)$ & $65(38.9)$ & $102(61.1)$ & Reference & \\
\hline Praziquantel & $135(44.7)$ & $48(35.6)$ & $87(64.4)$ & $0.47(-0.07,1.00)$ & 0.09 \\
\hline \multicolumn{6}{|c|}{ Household socioeconomic status recorded at EMaBS enrolment ${ }^{\mathrm{d}}(n, \%)(\mathrm{mv}=5)$} \\
\hline 1 (lowest) & $16(5.4)$ & $13(81.3)$ & 3(18.7) & $-1.49(-2.92,-0.07)$ & \\
\hline 2 & $16(5.4)$ & $6(37.5)$ & $10(62.5)$ & $-1.26(-2.77,0.24)$ & \\
\hline 3 & $82(27.6)$ & $22(26.8)$ & $60(73.2)$ & $0.33(-0.71,1.37)$ & \\
\hline 4 & $89(29.9)$ & $30(33.7)$ & $59(66.3)$ & $-0.14(-1.18,0.89)$ & \\
\hline 5 & $69(23.2)$ & $29(42.0)$ & $40(58.0)$ & $-0.33(-1.39,0.72)$ & \\
\hline 6 (highest) & $25(8.4)$ & $11(44.0)$ & $14(56.0)$ & Reference & 0.25 * \\
\hline \multicolumn{6}{|c|}{ Location recorded at EMaBS enrolment $(n, \%)$} \\
\hline Urban & $118(39.1)$ & $49(41.5)$ & $69(58.5)$ & Reference & \\
\hline Peri-urban & $79(26.2)$ & $29(36.7)$ & $50(63.3)$ & $0.36(-0.33,1.05)$ & \\
\hline Rural & $105(34.8)$ & $35(33.3)$ & $70(66.7)$ & $0.24(-0.41,0.89)$ & $0.45^{*}$ \\
\hline
\end{tabular}

$\mathrm{SD}$, standard deviation; mv, missing values. ${ }^{a}$ Anaemia as haemoglobin $<11 \mathrm{~g} / \mathrm{dL}$, adjusted for change in altitude (1000 m above sea level); ${ }^{b}$ iron deficiency as ferritin levels $<12 \mu \mathrm{g} / \mathrm{L}$; and ${ }^{\mathrm{c}}$ inflammation as C-reactive protein levels $>5 \mathrm{mg} / \mathrm{L}$. ${ }^{\mathrm{d}}$ Household socioeconomic status was derived as a composite of building materials of the home, number of rooms and items owned. t+All multivariable models were adjusted for all the other participant characteristics (age at 25(OH)D measurement, sex, iron status, anaemia, inflammation, weight-for-height Z-scores, helminthic infections between birth and 5 years, randomized treatment of children and mothers with albendazole and praziquantel, household socioeconomic status, location, maternal age and education, parity and asymptomatic malaria parasitaemia. Sample size reduced from 302 to 295 children in the final multivariable analyses due to missing values in some of the adjusted variables such as anaemia and iron status. ${ }^{*} p$ value for trend.

In this population, stunting at age 5 years was more common (34.4\%) than underweight $(11.1 \%)$ or wasting $(4.7 \%)$. Malaria was common, with $55.3 \%$ children having had at least one episode of clinical malaria while $11.3 \%$ had asymptomatic malaria parasitaemia at an annual visit between birth and five years. Over a third of the children were anaemic, while $27.1 \%$ were iron deficient and $23.1 \%$ had inflammation at the time of $25(\mathrm{OH}) \mathrm{D}$ measurement. The majority of participants resided in urban $(39.1 \%)$ or peri-urban $(26.2 \%)$ areas (Table 2$)$. Of 302 children, four (1.3\%) were HIV positive at 18 months and of 300 children with available data, four $(1.7 \%)$ were delivered preterm $(<37$ gestational weeks). Baseline characteristics were comparable between participants included in the analyses and 
those not included, with the exception that stunting was more common while asymptomatic malaria parasitaemia was less common among participants than those not included. Participants were more likely to have higher socioeconomic status while mothers of participants were older and had higher parity compared to children who were not included (Supplementary Table S1).

\subsection{Associations Between 25(OH)D and Participant Characteristics}

In the multivariable analyses we observed evidence of a decreasing trend of $25(\mathrm{OH}) \mathrm{D}$ levels with increasing child age and asymptomatic malaria was associated with high $25(\mathrm{OH}) \mathrm{D}$ levels. Inflammation was associated with higher mean $25(\mathrm{OH}) \mathrm{D}$ levels and $25(\mathrm{OH}) \mathrm{D}$ levels $>75 \mathrm{nmol} / \mathrm{L}$ were more common among those with inflammation than for those with lower CRP levels (Table 2).

\subsection{Cognitive and Motor Outcomes at Five Years and Associations with Participant Characteristics}

The IQ, EF and motor function scores were normally distributed. Mean scores for the individual tests that were used to assess cognitive and motor outcomes are presented in Supplementary Table S2. Girls had higher EF and motor scores compared to boys after adjusting for potential confounders, but there was no difference by sex for IQ scores (Table 3). Children who were randomly allocated placebo in the original EMaBS trial had lower motor scores compared to those who received albendazole, but little difference was observed in IQ and EF scores (Table 3). Stunting, low socioeconomic status and low levels of maternal education were associated with lower IQ scores in univariable analyses but not after adjusting for potential confounders. No associations were observed with other participant characteristics in univariable analyses (Supplementary Table S3).

Table 3. Multivariable linear regression results for associations between participant characteristics and outcomes.

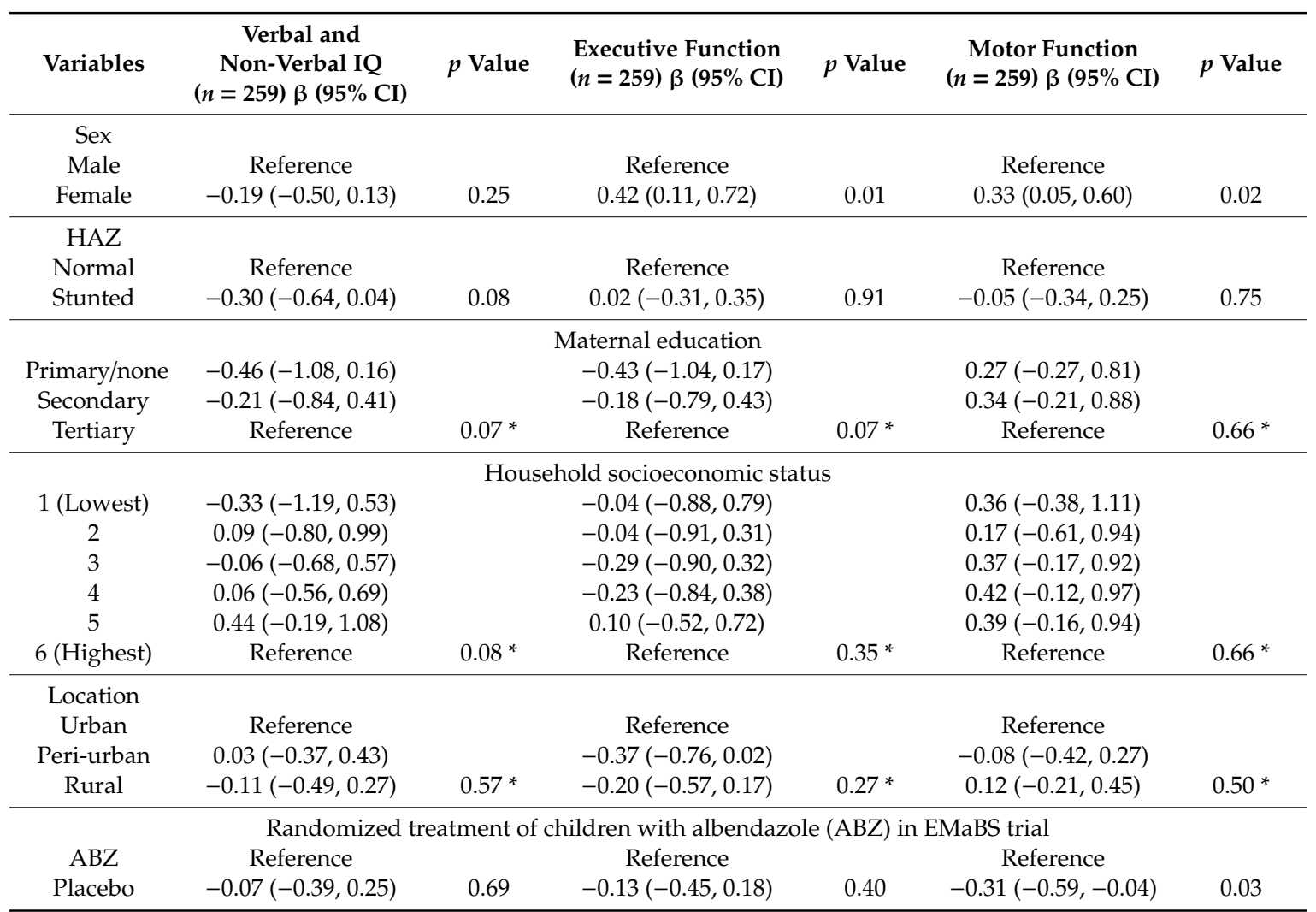

$\mathrm{CI}$, confidence interval; IQ, intelligence quotient; HAZ, height-for-age Z-scores. All models are adjusted for age at $25(\mathrm{OH}) \mathrm{D}$ measurement, $25(\mathrm{OH}) \mathrm{D}$ levels, anaemia, iron status, inflammation and asymptomatic malaria. Sample size reduced from 302 to 259 children in the final multivariable analyses due to missing values in some of the adjusted variables such as anaemia and iron status. ${ }^{*} p$ value for trend. 


\subsection{Associations between 25(OH)D and Cognitive and Motor Outcomes}

Table 4 shows the univariable and multivariable linear regression results for the effect of $25(\mathrm{OH}) \mathrm{D}$ levels on cognitive and motor outcomes. We observed little association between $25(\mathrm{OH}) \mathrm{D}$ levels and IQ, EF or motor function either in crude analysis or after adjusting for potential confounders. Considering $25(\mathrm{OH}) \mathrm{D}$ as a categorical variable, we found no evidence of differences in the mean scores among children with $25(\mathrm{OH}) \mathrm{D}$ levels $<50 \mathrm{nmol} / \mathrm{L}, 50-75 \mathrm{nmol} / \mathrm{L}$ and $>75 \mathrm{nmol} / \mathrm{L}$ for IQ $(p=0.89)$, EF $(p=0.44)$ or motor function $(p=0.44)$ outcomes. We found little evidence of association between IQ, EF or motor function and $25(\mathrm{OH}) \mathrm{D}$ levels $\leq 75 \mathrm{nmol} / \mathrm{L}$ compared to levels $>75 \mathrm{nmol} / \mathrm{L}$ or for levels $50-75 \mathrm{nmol} / \mathrm{L}$ compared to levels $>75 \mathrm{nmol} / \mathrm{L}$ after adjusting for potential confounders (Table 4 ).

Table 4. Univariable and multivariable linear regression results for the association between $25(\mathrm{OH}) \mathrm{D}$ levels and cognitive and motor outcomes.

\begin{tabular}{|c|c|c|c|c|c|c|}
\hline & $\begin{array}{l}\text { Univariable Model } \\
\beta(95 \% \text { CI }) n=302\end{array}$ & $p$ Value & $\begin{array}{c}\text { Model } 1 * \beta(95 \% \\
\text { CI) } n=272\end{array}$ & $p$ Value & $\begin{array}{c}\text { Model } 2 * * \beta(95 \% \\
\text { CI) } n=259\end{array}$ & $p$ Value \\
\hline \multicolumn{7}{|c|}{ Verbal and non-verbal IQ } \\
\hline 25(OH)D levels (per $10 \mathrm{nmol} / \mathrm{L}$ ) & $-0.01(-0.07,0.06)$ & 0.76 & $0.01(-0.07,0.08)$ & 0.86 & $0.01(-0.07,0.08)$ & 0.82 \\
\hline $25(\mathrm{OH}) \mathrm{D}$ levels $>75 \mathrm{nmol} / \mathrm{L}$ & Reference & & Reference & & Reference & \\
\hline $25(\mathrm{OH}) \mathrm{D}$ levels $50-75 \mathrm{nmol} / \mathrm{L}$ & $-0.08(-0.40,0.24)$ & 0.63 & $0.02(-0.31,0.35)$ & 0.89 & $0.04(-0.30,0.39)$ & 0.80 \\
\hline $25(\mathrm{OH}) \mathrm{D}$ levels $\leq 75 \mathrm{nmol} / \mathrm{L}$ & $0.08(-0.23,0.39)$ & 0.63 & $-0.01(-0.33,0.32)$ & 0.96 & $-0.05(-0.38,0.29)$ & 0.78 \\
\hline \multicolumn{7}{|c|}{ Executive function } \\
\hline 25(OH)D levels (per $10 \mathrm{nmol} / \mathrm{L}$ ) & $0.01(-0.06,0.07)$ & 0.81 & $0.03(-0.04,0.10)$ & 0.37 & $0.04(-0.03,0.12)$ & 0.25 \\
\hline $25(\mathrm{OH}) \mathrm{D}$ levels $>75 \mathrm{nmol} / \mathrm{L}$ & Reference & & Reference & & Reference & \\
\hline $25(\mathrm{OH}) \mathrm{D}$ levels $50-75 \mathrm{nmol} / \mathrm{L}$ & $-0.07(-0.38,0.23)$ & 0.64 & $-0.06(-0.38,0.27)$ & 0.73 & $-0.04(-37,0.29)$ & 0.81 \\
\hline 25(OH)D levels $\leq 75$ nmol/L & $0.08(-0.22,0.39)$ & 0.58 & $0.04(-0.27,0.35)$ & 0.80 & $0.01(-0.32,0.34)$ & 0.94 \\
\hline \multicolumn{7}{|c|}{ Motor function } \\
\hline 25(OH)D levels (per $10 \mathrm{nmol} / \mathrm{L}$ ) & $0.02(-0.04,0.07)$ & 0.54 & $0.02(-0.04,0.08)$ & 0.55 & $0.02(-0.04,0.09)$ & 0.52 \\
\hline $25(\mathrm{OH}) \mathrm{D}$ levels $>75 \mathrm{nmol} / \mathrm{L}$ & Reference & & Reference & & Reference & \\
\hline 25(OH)D levels $50-75 \mathrm{nmol} / \mathrm{L}$ & $0.00(-0.27,0.27)$ & 0.99 & $0.01(-0.27,0.29)$ & 0.96 & $0.01(-0.29,0.30)$ & 0.97 \\
\hline $25(\mathrm{OH}) \mathrm{D}$ levels $\leq 75 \mathrm{nmol} / \mathrm{L}$ & $-0.04(-0.29,0.22)$ & 0.79 & $-0.06(-0.33,0.22)$ & 0.68 & $-0.06(-0.34,0.23)$ & 0.70 \\
\hline
\end{tabular}

CI, confidence interval. * Model 1 was minimally adjusted for age at 25(OH)D measurement, sex, iron status and anaemia. ${ }^{* *}$ Model 2 was adjusted for factors in model 1 plus stunting, inflammation, randomized treatment of children with albendazole, socioeconomic status, maternal education and asymptomatic malaria parasitaemia. Sample size reduced from 302 to 259 children in the final multivariable analyses due to missing values in some of the adjusted variables such as anaemia and iron status. All $p$ values are from the Wald test.

\section{Discussion}

We evaluated the association between $25(\mathrm{OH}) \mathrm{D}$ levels measured in young Ugandan children below five years and their cognitive and motor outcomes at five years of age. In this study population, we found that few children had $25(\mathrm{OH}) \mathrm{D}$ levels $<50 \mathrm{nmol} / \mathrm{L}(2.7 \%)$, and the majority of children $(62.6 \%)$ had $25(\mathrm{OH}) \mathrm{D}$ levels $>75 \mathrm{nmol} / \mathrm{L}$. We found no evidence of association between vitamin $\mathrm{D}$ status and IQ, EF or motor function. This finding may be explained by the small proportion of children with $25(\mathrm{OH}) \mathrm{D}$ levels $<50 \mathrm{nmol} / \mathrm{L}$ limiting the ability to detect an effect, especially if $25(\mathrm{OH}) \mathrm{D}$ levels $<50$ $\mathrm{nmol} / \mathrm{L}$, rather than $25(\mathrm{OH}) \mathrm{D}$ levels $\leq 75 \mathrm{nmol} / \mathrm{L}$, drives impaired neurobehavioural outcomes [33]. Girls had higher EF and motor scores compared to boys but there was no difference by sex for IQ scores. Children who were randomly allocated placebo in the original trial had marginally lower motor scores compared to those who received albendazole, but we did not observe differences in IQ and EF scores.

Our findings of no association between vitamin D status and cognitive or motor function, agree with nine previous observational studies [34-42]. On the contrary, a small dose-response randomized controlled trial $(n=55)$ of vitamin D supplementation in Canadian infants reported that a lower dose of 400 international units (IU) of vitamin D was more beneficial for gross motor development than higher doses of 800 IU or 1200 IU [16]. This finding may indicate a threshold effect for vitamin D but may be limited by the small sample size and lack of a control group that did not receive vitamin D supplements. Additionally, a cross-sectional study of one-year-old Iranian children $(n=186)$ reported a positive association between high 25(OH)D levels and improved motor function [43]. To our knowledge, ours is the first prospective study to investigate the relationship between vitamin $\mathrm{D}$ status and cognitive and 
motor development in pre-school children in sub-Saharan Africa. To date, only three observational studies have evaluated the effect of child or maternal vitamin D status on neurobehavioural outcomes in African children. One prospective study $(n=254)$ observed an association between increasing 25(OH)D levels and improved socioemotional adjustment in Ugandan school-aged children who were HIV negative and those perinatally exposed to HIV but uninfected and unexposed to early antiretroviral therapy (ART) [18]. They also observed an association between increasing 25(OH)D levels and poor socioemotional adjustment in HIV-infected children and in HIV-uninfected children exposed to early ART, which may be attributed to dysregulation of 25(OH)D metabolism by ART. Another small study $(n=45)$ reported that high $25(\mathrm{OH}) \mathrm{D}$ levels were positively associated with improved cognition in Egyptian school-aged children [19]. Additionally, an observational study of 202 mother-child pairs in Seychelles reported no association between maternal 25(OH)D levels during pregnancy and neurobehavioural outcomes at five years [44].

Contrary to our findings, animal and in vitro studies provide consistent evidence for the adverse effects of vitamin D deficiency on neurodevelopment and possible mechanisms for this effect. The presence of vitamin D receptors and metabolism enzymes in parts of the brain involved in cognition suggests that vitamin D may be important for cognition [45]. Similarly, the presence of vitamin $\mathrm{D}$ receptors in skeletal muscles suggests that vitamin $\mathrm{D}$ is important for muscle development and subsequent motor function. Experimental evidence shows reduced type II muscle fibre diameter in mice whose skeletal muscle vitamin D receptors are knocked out [46]. Furthermore, vitamin D deficiency is implicated in alterations in neurotransmitter synthesis and synaptic plasticity which may affect learning processes, cognition $[11,47]$ and motor processes $[13,48]$. However, the application of these findings to humans may be limited as experimental studies are able to generate conditions of adverse vitamin D deficiency to an extent unlikely to be observed in humans. Additionally, it is unclear when $25(\mathrm{OH}) \mathrm{D}$ levels might influence neurobehavioural outcomes. Some observational studies in mother-child pairs suggest that levels of 25(OH)D influence neurobehavioural outcomes exclusively during the prenatal period [49-51]. However, other similar studies have reported little association between maternal 25(OH)D levels and neurobehavioural outcomes in children [52,53].

We observed a decreasing trend of $25(\mathrm{OH}) \mathrm{D}$ levels with increasing child age consistent with previous evidence [54]. Younger children may acquire $25(\mathrm{OH}) \mathrm{D}$ from their mothers through placental transfer of 25(OH)D in utero or breastfeeding during infancy. Asymptomatic malaria parasitaemia was associated with higher $25(\mathrm{OH}) \mathrm{D}$ levels. Evidence on the relationship between malaria and $25(\mathrm{OH}) \mathrm{D}$ levels is limited and inconclusive [55,56]. High 25(OH)D levels were associated with increased inflammation contrary to other studies that have shown possible anti-inflammatory properties of vitamin D [57]. We found that two other factors influenced neurobehavioural outcomes. Girls performed better in the EF and motor tests compared to boys, consistent with previous studies [58,59]. There is no clear evidence of the causes for the observed differences though they may be attributed to differences in environmental and socio-cultural factors between boys and girls [60]. It is also possible that the differences were a developmental pattern that changed after the pre-school age [61]. Furthermore, randomized treatment of children with albendazole in the EMaBS trial was marginally associated with higher motor scores compared to placebo treatment. This may be a chance finding since in the larger EMaBS birth cohort no associations were observed between either child or maternal treatment with albendazole and cognitive or motor scores $[62,63]$.

Strengths of our study include the extensive battery of tools used to measure cognitive and motor outcomes that were specifically validated and adapted to the Ugandan population [25]. Moreover, prospectively collected data on multiple covariates were available allowing adjustment for many potential confounders. Furthermore, we analysed $25(\mathrm{OH}) \mathrm{D}$ both as continuous and categorical variables which was important considering the lack of global consensus on vitamin D status cut-offs. Several limitations must be considered when interpreting our results. We included about $13 \%$ of participants in the original EMaBS birth cohort in our analyses as $25(\mathrm{OH}) \mathrm{D}$ levels and cognitive and motor outcomes were assessed in smaller subsets of participants and over a quarter of the original 
participants were lost to follow up. However, our study was adequately powered to detect the reported effect sizes, and selection bias was unlikely as most baseline characteristics were comparable between children who were included in these analyses and those who were not included. We were unable to assess the association between $25(\mathrm{OH}) \mathrm{D}$ levels $<50 \mathrm{nmol} / \mathrm{L}$ and cognitive and motor outcomes as only $2.7 \%$ children had $25(\mathrm{OH}) \mathrm{D}$ levels $<50 \mathrm{nmol} / \mathrm{L}$ in this study population. Additionally, plasma $25(\mathrm{OH}) \mathrm{D}$ levels were measured at one time-point prior to developmental assessment and may not reflect the vitamin D status of the children throughout early childhood or at the time of cognitive and motor assessment, which could lead to underestimation of the association between $25(\mathrm{OH}) \mathrm{D}$ and cognitive or motor outcomes. Further, the possibility of other unmeasured variables that may affect 25(OH)D levels cannot be ruled out. These include habits that might influence exposure to sunlight, for example, outdoor physical activity and clothing and dietary vitamin D intake. However, diet may not be an important risk factor since vitamin D fortification and supplementation is not routine in Uganda. There may have also been other unmeasured factors that might have influenced cognitive and motor outcomes, such as pre-schooling, inadequately stimulating home environment or maternal IQ. Additionally, other variables recoded at enrolment such as location and socioeconomic status of some participants may have changed over the study period which may possibly result in residual confounding for the associations between $25(\mathrm{OH}) \mathrm{D}$ and cognitive and motor outcomes.

\section{Conclusions}

In conclusion, our findings add to the evidence from similar studies that report no association between vitamin D status and cognitive and motor outcomes in children. This study adds to the very limited literature on the effect of vitamin D status on neurobehavioural outcomes in children from sub-Saharan Africa. Further longitudinal studies in populations with $25(\mathrm{OH}) \mathrm{D}$ levels $<50 \mathrm{nmol} / \mathrm{L}$ and well-conducted randomized controlled trials of vitamin D supplementation would be valuable in clarifying the causal effect of vitamin D status in early childhood for cognitive and motor development.

Supplementary Materials: The following are available online at http://www.mdpi.com/2072-6643/12/6/1662/s1, Table S1: Comparison of baseline characteristics between children who were included in this analysis and children who were excluded due to loss to follow up or death or missing $25(\mathrm{OH}) \mathrm{D}$ and/or cognitive and motor outcome data. Table S2: Summary of cognitive and motor development scores, Table S3: Univariable linear regression results for the association between exposure variables and outcomes.

Author Contributions: A.M.M., S.H.A., A.A., E.L.W., M.N. and A.M.E. conceptualized the study and obtained the relevant data transfer authorization. A.M.E., S.H.A, E.L.W. and M.N. provided the datasets. A.M.M. and E.L.W. conducted the formal analysis. M.N. and A.A. advised and validated the combination of developmental outcomes using principal components analyses. A.M.M. and S.H.A. wrote the first draft and A.M.M., S.H.A., A.A., M.N., J.M.P., T.N.W., E.L.W. and A.M.E. reviewed and edited successive drafts of the paper and approved the final version. All authors have read and agreed to the published version of the manuscript.

Funding: This work was supported by Wellcome [Grant numbers 209640 to A.M.M., 110255 to S.H.A., 202800 to TNW, 064693, 079110, 095778 to A.M.E.] and and with core awards to the KEMRI-Wellcome Trust Research Programme (203077) and by the Medical Research Council [Grant number MR/M025454/1 to A.A.]. The funders had no role in the design and conduct of the study, manuscript preparation or interpretation of the findings.

Acknowledgments: We acknowledge the permission of the Director of the Kenya Medical Research Institute (KEMRI) for publication.

Conflicts of Interest: The authors declare no conflict of interest.

\section{References}

1. Shonkoff, J.P.; Phillips, D.A. From neurons to neighborhoods: The science of early childhood development; National Academies Press: Washington, DC, USA, 2000; pp. 182-185.

2. McCoy, D.C.; Peet, E.D.; Ezzati, M.; Danaei, G.; Black, M.M.; Sudfeld, C.R.; Fawzi, W.; Fink, G. Early childhood developmental status in low-and middle-income countries: National, regional, and global prevalence estimates using predictive modeling. PLoS Med. 2016, 13, e1002034. [CrossRef] [PubMed] 
3. Black, M.M.; Walker, S.P.; Fernald, L.C.; Andersen, C.T.; DiGirolamo, A.M.; Lu, C.; McCoy, D.C.; Fink, G.; Shawar, Y.R.; Shiffman, J. Early childhood development coming of age: Science through the life course. The Lancet 2017, 389, 77-90. [CrossRef]

4. Black, M.M. Micronutrient deficiencies and cognitive functioning. J. Nutr. 2003, 133, 3927S-3931S. [CrossRef] [PubMed]

5. Lips, P. Vitamin D physiology. Prog. Biophys. Mol. Biol. 2006, 92, 4-8. [CrossRef]

6. Wahl, D.; Cooper, C.; Ebeling, P.; Eggersdorfer, M.; Hilger, J.; Hoffmann, K.; Josse, R.; Kanis, J.; Mithal, A.; Pierroz, D. A global representation of vitamin D status in healthy populations. Arch. Osteoporos. 2012, 7, 155-172. [CrossRef]

7. Hilger, J.; Friedel, A.; Herr, R.; Rausch, T.; Roos, F.; Wahl, D.A.; Pierroz, D.D.; Weber, P.; Hoffmann, K. A systematic review of vitamin D status in populations worldwide. Br. J. Nutr. 2014, 111, 23-45. [CrossRef]

8. Roth, D.E.; Abrams, S.A.; Aloia, J.; Bergeron, G.; Bourassa, M.W.; Brown, K.H.; Calvo, M.S.; Cashman, K.D.; Combs, G.; De-Regil, L.M. Global prevalence and disease burden of vitamin D deficiency: A roadmap for action in low-and middle-income countries. Ann. NY Acad. Sci. 2018, 1430, 44-79. [CrossRef]

9. Mogire, R.M.; Mutua, A.; Kimita, W.; Kamau, A.; Bejon, P.; Pettifor, J.M.; Adeyemo, A.; Williams, T.N.; Atkinson, S.H. Prevalence of vitamin D deficiency in Africa: A systematic review and meta-analysis. The Lancet Glob. Health 2019, 8, e134-e142. [CrossRef]

10. Harms, L.R.; Burne, T.H.; Eyles, D.W.; McGrath, J.J. Vitamin D and the brain. Best Pract. Res. Clin. Endocrinol. Metab. 2011, 25, 657-669. [CrossRef]

11. Al-Harbi, A.N.; Khan, K.M.; Rahman, A. Developmental Vitamin D Deficiency Affects Spatial Learning in Wistar Rats. J. Nutr. 2017, 147, 1795-1805. [CrossRef]

12. De Abreu, D.A.F.; Nivet, E.; Baril, N.; Khrestchatisky, M.; Roman, F.; Féron, F. Developmental vitamin D deficiency alters learning in C57Bl/6J mice. Behav. Brain Res. 2010, 208, 603-608. [CrossRef]

13. Kesby, J.P.; Cui, X.; Ko, P.; McGrath, J.J.; Burne, T.H.; Eyles, D.W. Developmental vitamin D deficiency alters dopamine turnover in neonatal rat forebrain. Neurosci. Lett. 2009, 461, 155-158. [CrossRef]

14. AlJohri, R.; AlOkail, M.; Haq, S.H. Neuroprotective role of vitamin D in primary neuronal cortical culture. eNeurologicalSci 2019, 14, 43-48. [CrossRef]

15. Mutua, A.M.; Mogire, R.M.; Elliott, A.M.; Williams, T.N.; Webb, E.L.; Abubakar, A.; Atkinson, S.H. Effects of vitamin D deficiency on neurobehavioural outcomes in children: A systematic review. Wellcome Op. Res. 2020, 5, 28. [CrossRef]

16. Wicklow, B.; Gallo, S.; Majnemer, A.; Vanstone, C.; Comeau, K.; Jones, G.; L'Abbe, M.; Khamessan, A.; Sharma, A.; Weiler, H. Impact of vitamin D supplementation on gross motor development of healthy term infants: A randomized dose-response trial. Phys. Occup. Ther. Pediatr. 2016, 36, 330-342. [CrossRef]

17. Salas, A.A.; Woodfin, T.; Phillips, V.; Peralta-Carcelen, M.; Carlo, W.A.; Ambalavanan, N. Dose-response effects of early vitamin D supplementation on neurodevelopmental and respiratory outcomes of extremely preterm infants at 2 years of age: A randomized trial. Neonatology 2018, 113, 256-262. [CrossRef]

18. Yakah, W.; Fenton, J.I.; Sikorskii, A.; Zalwango, S.K.; Tuke, R.; Musoke, P.; Boivin, M.J.; Giordani, B.; Ezeamama, A.E. Serum Vitamin D is Differentially Associated with Socioemotional Adjustment in Early School-Aged Ugandan Children According to Perinatal HIV Status and In Utero/Peripartum Antiretroviral Exposure History. Nutrients 2019, 11, 1570. [CrossRef]

19. Nassar, M.F.; Amin, D.A.; Hamed, A.I.; Nassar, J.F.; Abou-Zeid, A.-E.K.; Attaby, M.A. Vitamin D status and scholastic achievement in middle age childhood. J. Egypt. Soc. Parasitol. 2012, 240, 1-10. [CrossRef]

20. Elliott, A.M.; Kizza, M.; Quigley, M.A.; Ndibazza, J.; Nampijja, M.; Muhangi, L.; Morison, L.; Namujju, P.B.; Muwanga, M.; Kabatereine, N. The impact of helminths on the response to immunization and on the incidence of infection and disease in childhood in Uganda: Design of a randomized, double-blind, placebo-controlled, factorial trial of deworming interventions delivered in pregnancy and early childhood [ISRCTN32849447]. Clin. Trials. 2007, 4, 42-57.

21. Nabeta, H.W.; Kasolo, J.; Kiggundu, R.K.; Kiragga, A.N.; Kiguli, S. Serum vitamin D status in children with protein-energy malnutrition admitted to a national referral hospital in Uganda. BMC Res. Notes. 2015, 8, 418. [CrossRef]

22. Nampijja, M. The Impact of Helminth Infections on Developmental and Educational Outcomes. In Handbook of Applied Developmental Science in Sub-Saharan Africa; Abubakar, A., Van de Vijver, F., Eds.; Springer: New York, NY, USA, 2017; pp. 133-156. 
23. Muriuki, J.M.; Mentzer, A.J.; Kimita, W.; Ndungu, F.M.; Macharia, A.W.; Webb, E.L.; Lule, S.A.; Morovat, A.; Hill, A.V.; Bejon, P. Iron status and associated malaria risk among African children. Clin. Infect. Dis. 2018, 68, 1807-1814. [CrossRef]

24. Endocrine Society: clinical practice guidelines for vitamin D deficiency. Available online: https://www.healio.com/endocrinology/practice-management/news/online/\%7Bf7557f26-0d85-4ec8a33a-ef05f41e0e94\%7D/endocrine-society-publishes-clinical-practice-guidelines-for-vitamin-d-deficiency (accessed on 24 July 2019).

25. Nampijja, M.; Apule, B.; Lule, S.; Akurut, H.; Muhangi, L.; Elliott, A.; Alcock, K.J. Adaptation of Western measures of cognition for assessing 5-year-old semi-urban Ugandan children. Br. J. Educ. Psychol. 2010, 80, 15-30. [CrossRef] [PubMed]

26. Elliott, C.S.; McCulloch, K. The British Ability Scales, 3rd ed.; National Foundation for Psychological Research: Windsor, UK, 1996.

27. Holding, P.A.; Taylor, H.G.; Kazungu, S.D.; Mkala, T.; Gona, J.; Mwamuye, B.; Mbonani, L.; Stevenson, J. Assessing cognitive outcomes in a rural African population: Development of a neuropsychological battery in Kilifi District, Kenya. J. Int. Neuropsychol. Soc. 2004, 10, 246-260. [CrossRef]

28. Korkman, M.; Kirk, U.; Kemps, A. A developmental Neuropsychological Assessment; Harcourt Assessment: San Antonio, TX, USA, 1998.

29. Manly, T.; Anderson, V.; Nimmo-Smith, I.; Turner, A.; Watson, P.; Robertson, I.H. The differential assessment of children's attention: The Test of Everyday Attention for Children (TEA-Ch), normative sample and ADHD performance. J. Child Psychol. Psychiatry. 2001, 42, 1065-1081. [CrossRef] [PubMed]

30. Berg, E.A. A simple objective technique for measuring flexibility in thinking. J. Gen. Psychol. 1948, 39, 15-22. [CrossRef] [PubMed]

31. Abubakar, A.; Holding, P.; Van Baar, A.; Newton, C.; van de Vijver, F.J. Monitoring psychomotor development in a resourcelimited setting: An evaluation of the Kilifi Developmental Inventory. Ann. Trop. Paediatr. 2008, 28, 217-226. [CrossRef]

32. Henderson, S.E.; Sugden, D. Movement assessment battery for children, 1st ed.; The Psychological Corporation: London, UK, 1992.

33. Baksi, S.N.; Hughes, M.J. Chronic vitamin D deficiency in the weanling rat alters catecholamine metabolism in the cortex. Brain Res. 1982, 242, 387-390. [CrossRef]

34. Chowdhury, R.; Taneja, S.; Bhandari, N.; Kvestad, I.; Strand, T.A.; Bhan, M.K. Vitamin-D status and neurodevelopment and growth in young north Indian children: A secondary data analysis. Nutr. J. 2017, 16, 59. [CrossRef]

35. Chowdhury, R.; Taneja, S.; Kvestad, I.; Hysing, M.; Bhandari, N.; Strand, T.A. Vitamin D status in early childhood is not associated with cognitive development and linear growth at 6-9 years of age in North Indian children: a cohort study. Nutr. J. 2020, 19, 14. [CrossRef]

36. Filteau, S.; Rehman, A.M.; Yousafzai, A.; Chugh, R.; Kaur, M.; Sachdev, H.; Trilok-Kumar, G. Associations of vitamin D status, bone health and anthropometry, with gross motor development and performance of school-aged Indian children who were born at term with low birth weight. BMJ Open 2016, 6, e009268. [CrossRef]

37. Rahman, A.; Al-Taiar, A.; Shaban, L.; Al-Sabah, R.; Al-Harbi, A.; Mojiminiyi, O. Plasma 25-hydroxy vitamin $\mathrm{D}$ is not associated with either cognitive function or academic performance in adolescents. Nutrients 2018, 10, 1197. [CrossRef] [PubMed]

38. Schmidt, R.J.; Niu, Q.; Eyles, D.W.; Hansen, R.L.; Iosif, A.M. Neonatal vitamin D status in relation to autism spectrum disorder and developmental delay in the CHARGE case-control study. Autism Res. 2019, 12, 976-988. [CrossRef] [PubMed]

39. Tolppanen, A.M.; Williams, D.; Lawlor, D.A. The association of circulating 25-hydroxyvitamin D and calcium with cognitive performance in adolescents: Cross-sectional study using data from the third National Health and Nutrition Examination Survey. Paediatr. Perinat. Epidemiol. 2011, 25, 67-74. [CrossRef]

40. Trilok-Kumar, G.; Kaur, M.; Rehman, A.M.; Arora, H.; Rajput, M.M.; Chugh, R.; Kurpad, A.; Sachdev, H.S.; Filteau, S. Effects of vitamin D supplementation in infancy on growth, bone parameters, body composition and gross motor development at age 3-6 years: Follow-up of a randomized controlled trial. Int. J. Epidemiol 2015, 44, 894-905. [CrossRef] 
41. Windham, G.C.; Pearl, M.; Anderson, M.C.; Poon, V.; Eyles, D.; Jones, K.L.; Lyall, K.; Kharrazi, M.; Croen, L.A. Newborn vitamin D levels in relation to autism spectrum disorders and intellectual disability: A case-control study in California. Autism Res. 2019, 12, 989-998. [CrossRef]

42. Tofail, F.; Islam, M.M.; Mahfuz, M.; Ashraful Alam, M.; Aktar, S.; Haque, R.; Hossain, M.I.; Mondal, D.; Petri, W.A.; Ahmed, T. Association of vitamin D nutrition with neuro-developmental outcome of infants of slums in Bangladesh. PLoS ONE 2019, 14, e0221805. [CrossRef]

43. Tavakolizadeh, R.; Ardalani, M.; Shariatpanahi, G.; Mojtahedi, S.Y.; Sayarifard, A. Is There Any Relationship between Vitamin D Deficiency and Gross Motor Development in12-Month-Old Children? Iran. J. Child Neurol. 2019, 13, 55-60.

44. Laird, E.; Thurston, S.W.; van Wijngaarden, E.; Shamlaye, C.F.; Myers, G.J.; Davidson, P.W.; Watson, G.E.; McSorley, E.M.; Mulhern, M.S.; Yeates, A.J.; et al. Maternal vitamin D status and the relationship with neonatal anthropometric and childhood neurodevelopmental outcomes: Results from the Seychelles child development nutrition study. Nutrients 2017, 9, 1235. [CrossRef]

45. Marini, F.; Bartoccini, E.; Cascianelli, G.; Voccoli, V.; Baviglia, M.G.; Magni, M.V.; Garcia-Gil, M.; Albi, E. Effect of 1 $\alpha, 25$-dihydroxyvitamin D3 in embryonic hippocampal cells. Hippocampus 2010, 20, 696-705. [CrossRef]

46. Chen, S.; Villalta, S.A.; Agrawal, D.K. FOXO1 Mediates Vitamin D Deficiency-Induced Insulin Resistance in Skeletal Muscle. J. Bone Miner. Res. 2016, 31, 585-595. [CrossRef]

47. Taghizadeh, M.; Talaei, S.A.; Salami, M. Vitamin D deficiency impairs spatial learning in adult rats. Iran. Biomed. J. 2013, 17, 42-48. [PubMed]

48. Hawes, J.E.; Tesic, D.; Whitehouse, A.J.; Zosky, G.R.; Smith, J.T.; Wyrwoll, C.S. Maternal vitamin D deficiency alters fetal brain development in the BALB/c mouse. Behav. Brain Res. 2015, 286, 192-200. [CrossRef] [PubMed]

49. Darling, A.L.; Rayman, M.P.; Steer, C.D.; Golding, J.; Lanham-New, S.A.; Bath, S.C. Association between maternal vitamin D status in pregnancy and neurodevelopmental outcomes in childhood: Results from the Avon Longitudinal Study of Parents and Children (ALSPAC). Br. J. Nutr. 2017, 117, 1682-1692. [CrossRef]

50. Keim, S.A.; Bodnar, L.M.; Klebanoff, M.A. Maternal and cord blood $25(\mathrm{OH})$-vitamin D concentrations in relation to child development and behaviour. Paediatr. Perinat. Epidemiol. 2014, 28, 434-444. [CrossRef]

51. Zhu, P.; Tong, S.-L.; Hao, J.-H.; Tao, R.-X.; Huang, K.; Hu, W.-B.; Zhou, Q.-F.; Jiang, X.-M.; Tao, F.-B. Cord Blood Vitamin D and Neurocognitive Development Are Nonlinearly Related in Toddlers. J. Nutr. 2015, 145, 1232-1238. [CrossRef] [PubMed]

52. Gale, C.R.; Robinson, S.M.; Harvey, N.C.; Javaid, M.K.; Jiang, B.; Martyn, C.N.; Godfrey, K.M.; Cooper, C. Maternal vitamin D status during pregnancy and child outcomes. Eur. J. Clin. Nutr. 2008, 62, 68-77. [CrossRef]

53. Veena, S.R.; Krishnaveni, G.V.; Srinivasan, K.; Thajna, K.P.; Hegde, B.G.; Gale, C.R.; Fall, C.H. Association between maternal vitamin $\mathrm{D}$ status during pregnancy and offspring cognitive function during childhood and adolescence. Asia Pac. J. Clin. Nutr. 2017, 26, 438-449.

54. Zhu, Z.; Zhan, J.; Shao, J.; Chen, W.; Chen, L.; Li, W.; Ji, C.; Zhao, Z. High prevalence of vitamin D deficiency among children aged 1 month to 16 years in Hangzhou, China. BMC Public Health 2012, 12, 126. [CrossRef]

55. Cusick, S.E.; Opoka, R.O.; Lund, T.C.; John, C.C.; Polgreen, L.E. Vitamin D insufficiency is common in Ugandan children and is associated with severe malaria. PLoS ONE 2014, 9, e113185. [CrossRef]

56. Sudfeld, C.R.; Manji, K.P.; Smith, E.R.; Aboud, S.; Kisenge, R.; Fawzi, W.W.; Duggan, C.P. Vitamin D deficiency is not associated with growth or the incidence of common morbidities among Tanzanian infants. J. Pediatr. Gastroenterol. Nutr. 2017, 65, 467. [CrossRef] [PubMed]

57. Wöbke, T.K.; Sorg, B.L.; Steinhilber, D. Vitamin D in inflammatory diseases. Front. Physiol. 2014, 5, 244. [CrossRef]

58. Junaid, K.A.; Fellowes, S. Gender differences in the attainment of motor skills on the movement assessment battery for children. Phys. Occup. Ther. Pediatr. 2006, 26, 5-11. [CrossRef]

59. Flatters, I.; Hill, L.J.; Williams, J.H.; Barber, S.E.; Mon-Williams, M. Manual control age and sex differences in 4 to 11 year old children. PLoS ONE 2014, 9, e88692. [CrossRef] [PubMed]

60. Peyre, H.; Hoertel, N.; Bernard, J.Y.; Rouffignac, C.; Forhan, A.; Taine, M.; Heude, B.; Ramus, F.; EDEN Mother-Child Cohort Study Group. Sex differences in psychomotor development during the preschool period: A longitudinal study of the effects of environmental factors and of emotional, behavioral, and social functioning. J. Exp. Child. Psychol. 2019, 178, 369-384. [CrossRef] [PubMed] 
61. Malina, R.M.; Bouchard, C.; Bar-Or, O. Growth, maturation, and physical activity; Human kinetics: Champaign, IL, USA, 2004.

62. Ndibazza, J.; Mpairwe, H.; Webb, E.L.; Mawa, P.A.; Nampijja, M.; Muhangi, L.; Kihembo, M.; Lule, S.A.; Rutebarika, D.; Apule, B. Impact of anthelminthic treatment in pregnancy and childhood on immunisations, infections and eczema in childhood: a randomised controlled trial. PLoS ONE 2012, 7. [CrossRef] [PubMed]

63. Nampijja, M.; Apule, B.; Lule, S.; Akurut, H.; Muhangi, L.; Webb, E.L.; Lewis, C.; Elliott, A.M.; Alcock, K.J. Effects of maternal worm infections and anthelminthic treatment during pregnancy on infant motor and neurocognitive functioning. J. Int. Neuropsychol. Soc. 2012, 18, 1019-1030. [CrossRef] [PubMed]

(C) 2020 by the authors. Licensee MDPI, Basel, Switzerland. This article is an open access article distributed under the terms and conditions of the Creative Commons Attribution (CC BY) license (http://creativecommons.org/licenses/by/4.0/). 